\title{
International Orthopaedics
}

\author{
C) Springer-Verlag 1998
}

\section{Large synovial cyst of the pelvis containing rice bodies}

\author{
A case report \\ O. Tamai, T. Mamadi, Y. Muto, T. Toda \\ First Department of Surgery and Clinical Laboratory Medicine, Ryukyu University School of Medicine, Okinawa, Japan
}

Accepted: 15 October 1997

\begin{abstract}
Although synovial pelvic cysts are very uncommon they enter into the differential diagnosis of presacral and ovarian cysts. In the elderly male whom we report, a large cyst arose from the hip and extended during a five year period to involve the entire pelvic cavity. The cyst, which contained a large number of "rice bodies" was excised surgically.
\end{abstract}

Résumé. Bienque les kystes pelviens sont peu fréquents, exception faite des kystes présacraux chez l'enfant et des kystes ovariens, les kystes synoviaux doivent etre considérés comme diagnostic differenciel. Nous faisons le rapport d'un cas typique, chez lequel a été observé un volumineux kyste occupant presque toute la cavité pelvienne. Ce kyste a évolue dé façon progressive sur une période de 5 ans. La résection chirurgicale soigneuse, a mise en evidence une masse kystique d'environ $20 \mathrm{~cm}$ de diametre dont le contenu est fait de liquide brun sero-fibrineux avec des concretions sous forme de grains de riz.

\section{Introduction}

Synovial cysts of the hip, which are extremely rare, pose difficult problems in diagnosis and surgical treatment [1-3]. The rarity of this condition has prompted us to report the manifestations in a patient with an unusual pelvic cyst.

\footnotetext{
Reprint requests to: Dr. O. Tamai, First Department of Surgery, Ryukyu University School of Medicine, Nishihara-cho Uehara 207, Okinawa 903-01, Japan
}

\section{Case report}

An 83-year-old man was admitted in 1996 with a 5-year history of a painless mass on the right hip. There was no history of rheumatoid arthritis, pelvic trauma, or inflammatory disease of the pelvis. Physical examination revealed an oval cystic mass measuring $20 \mathrm{~cm}$ in its greatest diameter. It was not tender, did not pulsate and there was no bruit. The range of motion of the right hip was very limited. The lower abdomen was not distended and there were no palpable masses. Laboratory investigations including C-reactive protein, rheumatoid factor, and tumours markers (CEA, CA19-9) were normal.

Radiographs of the pelvis showed minor changes in both hip joints. No cyst was visualised. Computed tomography (CT) and magnetic resonance imaging (MRI) of the pelvis demonstrated cystic areas in the presacral region of the pelvic cavity and between the right hip and the sacrum. In addition, a spherical cystic cavity was present anterior to the right hip joint (Figs. 1, 2).

Surgical exploration was performed through a longitudinal incision over the swelling. The subcutaneous fat and fascia were found to be attenuated. Incision revealed a large, bulbous mass which was carefully delineated by sharp and blunt dissection. A clear communication between the hip joint and the cyst was not identified. The cyst was opened and it was filled with brown serous fluid containing numerous "rice bodies",

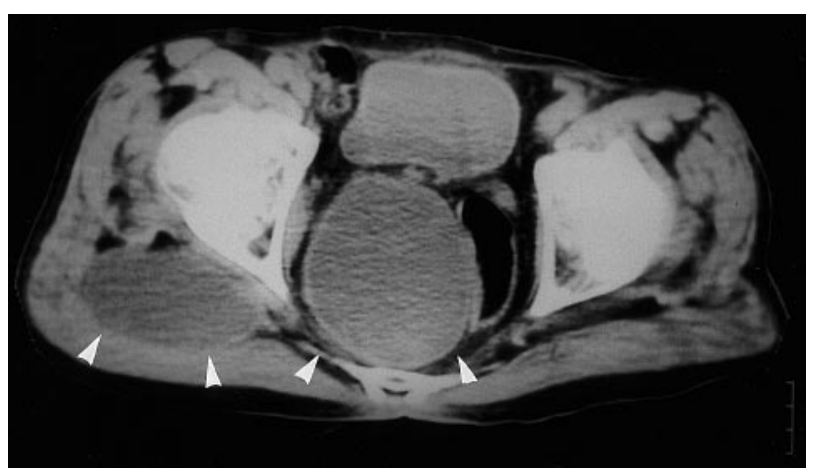

Fig. 1. CT of the hip revealed a bilocular cyst occupying most of the presacral space and right hip (arrow head) 


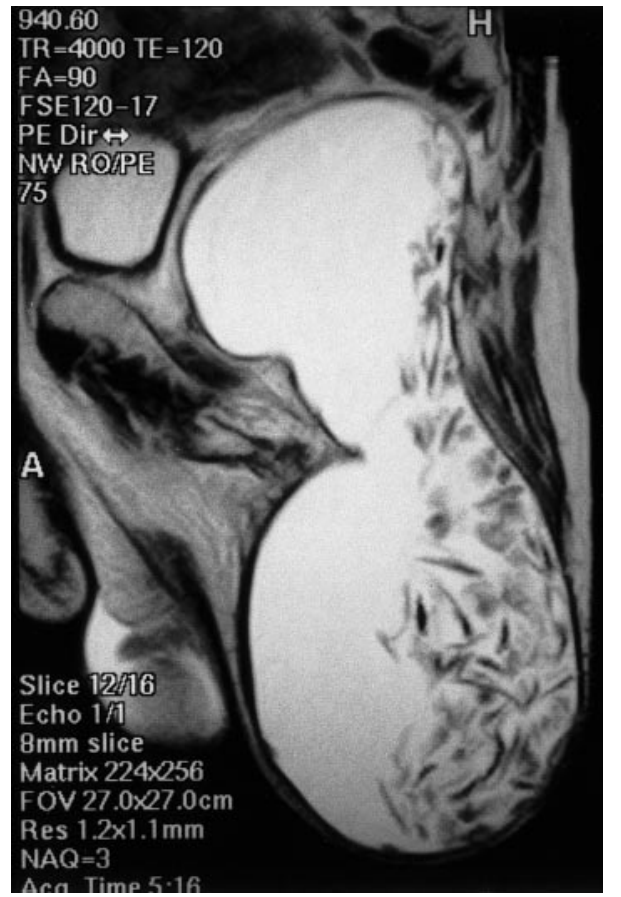

Fig. 2. Sagittal MRI imaging (supine position) demonstrating a sinuous elongated cyst measuring $30 \mathrm{~cm}$ from the sacral promontory to the hip. The cyst contained varieated structures shaped like glass fragments, up to a few $\mathrm{cm}$ in diameter

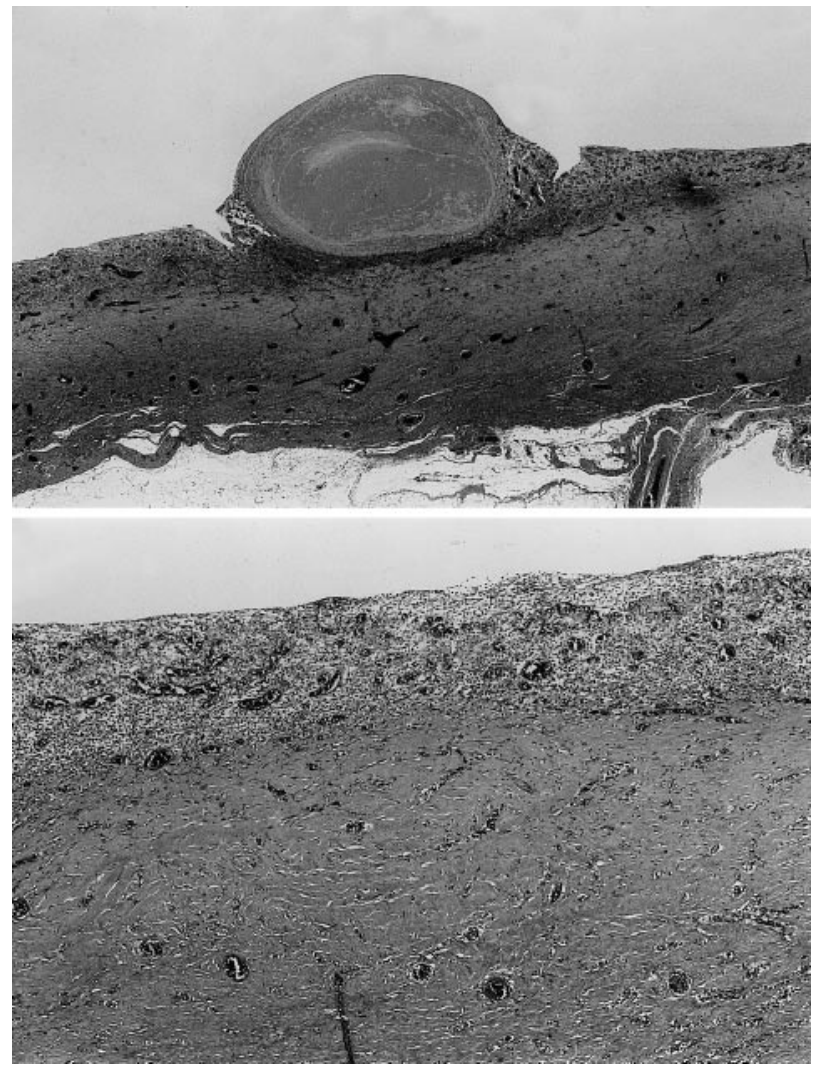

Fig. 3. Histologically the cyst wall shows a nodule (top, HE $\times 5)$ and inflammatory tissue with extensive cellular infiltrates and vascularity (bottom; $\mathrm{HE} \times 25$ )

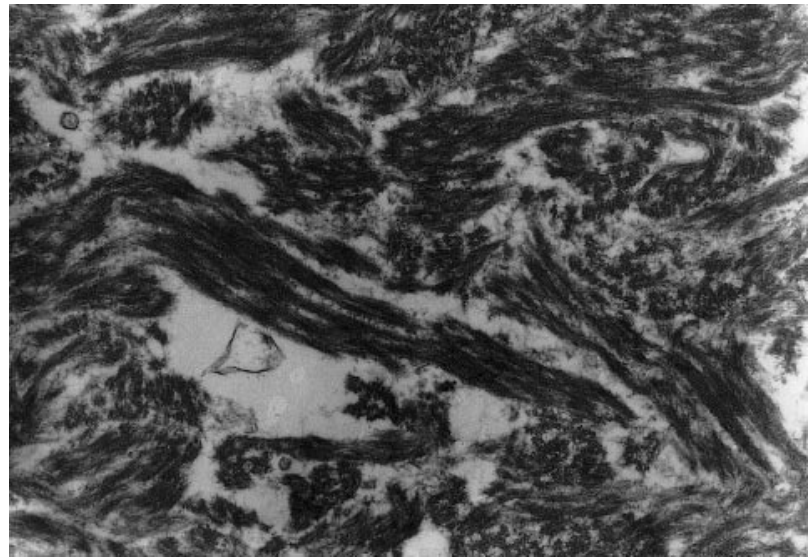

Fig. 4. Electron microscopical view of the rice bodies demonstrating the presence of fibrin $(\times 1500)$

each measuring approximately $1 \mathrm{~cm}$ in diameter. Microscopically, the cyst wall was composed of vascular synovial tissue which contained loose fibrous tissue and many small aggregates of lymphocytes and plasma cells. The inner surface was smooth and flat, without evidence of villi, and histologically it was lined with large synovial cells. The outer wall was composed of dense fibrous tissue and the entire surface was covered by acellular inflammatory debris and fibrin (Fig. 3). Throughout the tissue, many fibrinoid nodules of variable size were noted. The rice bodies seen in the cyst were composed of fibrin and did not stain for mucoprotein or lipoprotein. Electron microscopical investigation confirmed the nature of the rice bodies (Fig. 4). All findings were consistent with the diagnosis of a synovial cyst.

\section{Discussion}

There have been only a few reported instances of synovial cysts arising in the hip joint [3-8]. Synovial cysts are commonly associated with advanced rheumatoid arthritis, although of the large joints the hip is least affected [1-3]. Our patient had no history of rheumatoid arthritis and radiographs of his hip joints did not reveal any evidence of degenerative or ankylosing arthritis.

Cysts of the hip joints are generally attributed to trauma and infection, or to a spontaneous communication between the joint and an adjacent enlarged iliopsoas bursa $[4,9]$. Several theories have been postulated to explain the pathogenesis of synovial cysts of the hip [4]. The iliopsoas bursa sometimes communicates anteromedially with the hip joint and may become involved in the rheumatoid process [9]. If a direct communication between this bursa and the hip joint is not present, necrosis resulting from degenerative and rheumatoid changes, as well as pressure created from within the swollen bursa, may produce a communicating channel to the hip joint. The extensive vascular inflammatory response is associated with an abundant fibrinous surface exudate (rice bodies). Although these morphological changes are relatively non-specific and are often reported in chronic inflammation, vascular inflammation is an important feature of rheumatoid disease [1]. Based on the find- 
ings in our patient and others reported in the literature, a synovial cyst of unclear pathogenesis was diagnosed. Reports of iliopsoas bursitis suggest that this condition may be identical to the synovial cyst of the hip $[4,9,10]$.

Operation is recommended for the management of a synovial cyst of the hip and for exclusion of other diagnostic possibilities. The communicating stalk between the cyst and the hip joint should be ligated and divided surgically. It must be emphasised that treatment should be directed toward the underlying joint disease before considering steroid injection into a bursa, drainage, or bursectomy [8].

\section{References}

1. Bogumill GP, Schwamm HA (1984) Orthopaedic pathology. A synopsis with clinical and radiographic correlation. Saunders, Philadelphia, PA, pp 587-651

2. Jaffe HL ( 1972) Metabolic, degenerative, and inflammatory diseases of bones and joints. Lea \& Febiger, Philadelphia, PA, pp 781-806
3. Palmer DG (1969) Synovial cysts in rheumatoid diseases. Ann Intern Med 70: 61-68

4. Coventry MB, Polley HF, Weiner AD (1959) Rheumatoid synovial cyst of the hip. Report of three cases. J Bone Joint Surg [Am] 41: 721-730

5. White TK, Incavo SJ, Moreland MS (1988) Giant synovial cyst of the hip joint. Orthop Rev 17: 609-612

6. Forster BB, Connell DG, Scudamore CH (1989) Synovial cyst of the hip: an unusual cause of an inguinal mass. Can J Surg 32: 133-134

7. McGraw RW, Morton KS, Duncan CP (1991) Massive intrapelvic synovial cyst as a complication of total hip replacement arthroplasty: a case report. Can J Surg 34: 267-269

8. Bystrom S, Adalberth G, Milbrink J (1995) Giant synovial cyst of the hip: an unusual presentation with compression of the femoral vessels. Can J Surg 38: 368-370

9. Warren R, Kaye JJ, Salvati EA (1975) Arthrographic demonstration of an enlarged iliopsoas bursa complicating osteoarthritis of the hip. A case report. J Bone Joint Surg [Am] 57: 413-415

10. Underwood PL, McLeod RA, Ginsburg WW (1988) The varied clinical manifestations of iliopsoas bursitis. J Rheumatol 15: 1683-1685 